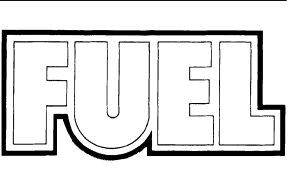

Fuel 79 (2000) 1395-1404

www.elsevier.com/locate/fuel

\title{
Methyldecalin hydrocracking over palladium/zeolite-X
}

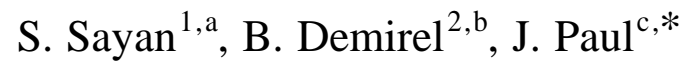 \\ ${ }^{a}$ Bilkent University, Chemistry, 06533 Bilkent-Ankara, Turkey \\ ${ }^{\mathrm{b}}$ University of Utah, Chemical and Fuels Engineering, Salt Lake City, UT 84112, USA \\ ${ }^{\mathrm{c}}$ Hacettepe University, Chemistry, 06532 Beytepe-Ankara, Turkey
}

Received 15 December 1998; received in revised form 15 November 1999; accepted 19 November 1999

\begin{abstract}
Hydrocracking of methyldecalin over Pd/REX has been studied with surface sensitive techniques in the critical temperature range 325$350^{\circ} \mathrm{C}$. Results from in situ characterization of adsorbed species, and post-reaction analysis of the catalyst surface by infrared and photoemission spectroscopies, were related to product distributions. The results are discussed in light of quantum chemical calculations of free and catalyst bound intermediates, following ring-opening reactions. Liquid and gaseous products were detected by infrared and UV/Vis spectroscopies. Apparent activation energies of product formation hydrogen consumption, over a broader temperature range, were derived from previous autoclave experiments.

An increase in temperature, $325-350^{\circ} \mathrm{C}$, results in a shift from preferred cracking products to aromatics, an enhanced level of light hydrocarbon off-gases, and a higher coverage of carbonaceous residues. The increased level of carbonaceous residues is accompanied by a lowered coverage of the reactant, at the surface. The altered product distribution can be characterized by apparent single activation energies, valid from 300 to $450^{\circ} \mathrm{C}$. Methane and aromatics show a similar rapid increase with temperature, hydrogen consumption a more timid increase, indicating a reaction limited by diffusion, and cycloalkane production a modest inverse temperature dependence.

Fully hydrogenated ring-opening products represent valuable fuel components, but hydrogen deficiency can instead lead to chemisorbed precursors to coke. Our calculations show that cyclohexane, 1,2-diethyl, 3-methyl has a lower heat of formation than the corresponding surface intermediates, but a small enthalpy advantage can easily be countered by entropy effects at higher temperatures. This balance is critical to the formation of preferred products, instead of catalyst deactivation and aromatics. The theoretical results further show that surface intermediates, where the terminating hydrogen is replaced by a C-O bond, have distinct vibrations around $1150 \mathrm{~cm}^{-1}$. C) $2000 \mathrm{Elsevier}$ Science Ltd. All rights reserved.
\end{abstract}

Keywords: Benzene; Cyclopropane; Cyclohexane

\section{Introduction}

Hydrocracking provides the refining industry with a diverse, although costly, process [1-3]. At elevated hydrogen pressures three reactions occur: (i) hydrogenation; (ii) isomerization; and (iii) cracking. The catalyst, temperature and residence time, are important parameters. The catalyst, often an oxide supported transition metal, is bifunctional with $\mathrm{C}-\mathrm{C}$ bond breaking and hydrogen addition over acid sites on the oxide and hydrogen dissociation on the metal.

\footnotetext{
* Corresponding author. Present address: Luleå University of Technology, Physics, 97187 Luleå, Sweden. Tel.: + 46-920-91793; fax: + 46920-91074.

E-mail address: jan.paul@mt.luth.se (J. Paul).

${ }^{1}$ Present address: Rutgers University, Chemistry, Piscataway, NJ 08854, USA.

${ }^{2}$ Present address: Center for Applied Energy Research, Lexington, KY 40511-8410, USA.
}

The purpose of the present work is to discuss reactions of methyldecahydronaphthalene (methyldecalin) over one catalyst, $\mathrm{Pd} / \mathrm{REX}$, at a critical temperature range, $325-350^{\circ} \mathrm{C}$, in the light of surface sensitive measurements. REX stands for rare earth exchange X-type zeolite [4-7].

Conversion, product distribution and potential for commercialization were recently demonstrated for an optimized two-stage process, converting 1-methylnaphthalene (MeNapht) to fuels components [8,9]. MeNapht is a model compound for heavy crude oil, coal derived liquids and oil shales. An initial hydrogenation step produced high yields of methyldecalins (MeDec) over a $\mathrm{NiMo} / \mathrm{TiO}_{2}-\mathrm{Al}_{2} \mathrm{O}_{3}$ catalyst [10]. A second hydrocracking step converted MeDec to fuel components over Pd/REX [9]. Within the above engineering framework several scientific challenges emerged. One challenge was to improve mass-balance evaluations, another to elucidate the importance of 
(a)

\section{Zeolite-X/1-Methyldecalin}

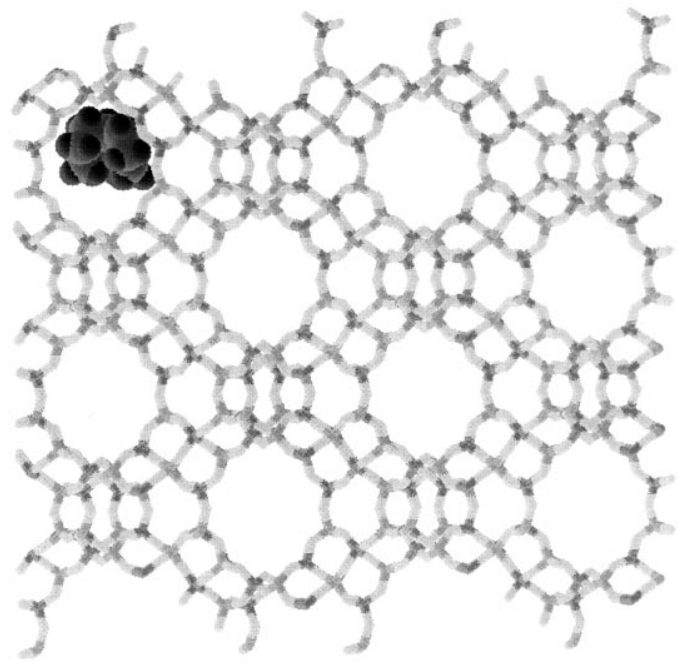

(b)

\section{Zeolite-X/Cyclohexane, 1,2-diethyl, 3-methyl}

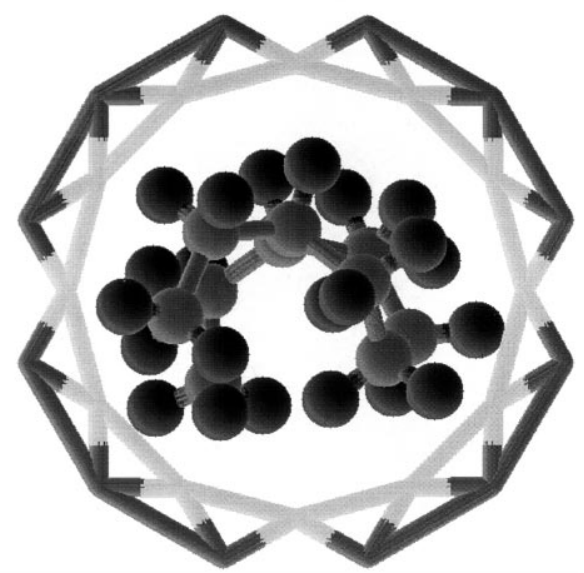

Fig. 1. (a) Pd/REX (zeolite-X) and 1-MeDec drawn to scale. (b) Cyclohexane, 1,2-diethyl, 3-methyl in zeolite-X, again drawn to scale. The geometry of zeolite$\mathrm{X}$ was given by the literature [24,26]. The geometries of free 1-MeDec and cyclohexane, 1,2-diethyl, 3-methyl were calculated in the HF/6-311G approximation.

carbonaceous residues, yet a third to look at molecular aspects of the reactions.

Activation and dissociation of $\mathrm{C}-\mathrm{C}$ bonds can occur via hybridization with electron states on a metal catalyst, via reactions with free radicals or via interaction with strong acids. Hybridization with metal orbitals readily occurs for unsaturated bonds, where the $\pi$-orbitals form a partially filled antibonding resonance in the vicinity of the highest occupied molecular orbital. For saturated bonds on metal catalysts the clue is to activate the $\mathrm{C}-\mathrm{C}$ bonds via perturbation of the $\mathrm{C}-\mathrm{H}$ bonds. This is achieved by piercing the hydrogen as deep as possible into the metal surface, thus filling the antibonding $\sigma^{*}$ level from the delocalized electrons of the metal. Cyclopropane is activated in this way on $C_{3 v}$ symmetric sites, and methane steam reforming occurs in a similar manner when the hot molecules collide with the nickel catalyst. Catalytic activation of $\mathrm{C}-\mathrm{C}$ bonds in the gas phase via unpaired electrons requires that molecular intermediates desorb as radicals, from the catalyst surface [11]. This occurs above the temperatures of hydroprocesses aiming at low levels of aromatic compounds in the product.

Models for the reaction paths of $\mathrm{C}-\mathrm{C}$ bond activation with acid catalysts often refer to the chemistry of carbonium (penta-coordinated carbon) and carbenium (tri-coordinated carbon) ions, and the mechanisms to form positively charged ions of common hydrocarbons [12,13]. Hydrogen must be transferred to the product of a ring-opening reaction in the initial step of the hydrocracking of MeDec. A C-C bond must be weakened and, eventually, broken and the resulting unpaired electrons on the two carbon atoms capped by two hydrogen atoms. Atomic hydrogen is generated by $\mathrm{H}-\mathrm{H}$ bond activation on metals, in the present case palladium, followed by diffusion to acid sites. One unwanted side reaction in this scheme is that a carbon atom reacts with the catalyst rather than with a hydrogen atom. Such a strong adsorption bond will likely lead to thermal fractioning of the chemisorbed hydrocarbon, thus leaving a carbonaceous residue on the oxide. This scenario can readily occur if the oxide is dehydrogenated, i.e. if the supply of hydrogen dwindles by deactivation of the supported metal or an unfavorable temperature, by lowered dispersion of the metal resulting in extended diffusion lengths for atomic hydrogen, or by an unfavorable geometry of the oxide.

Size effects in hydroprocessing of polycyclic compounds, over zeolitic catalysts, are a logical and relevant concern $[14,15]$. Hydrocracking of MeDec over zeolite- $X$ is in this respect most fortunate. The reactant is contained in a channel slightly wider than the molecular diameter (Fig. $1 \mathrm{a}$ and $\mathrm{b}$ ). After ring-opening and transfer of one hydrogen, hydroxyl groups surround the intermediate and the chances of finding a dehydrogenated site at normal temperatures and hydrogen activities are remote. More likely a second hydrogen will be transferred, leaving a stable product with a higher $\mathrm{H} / \mathrm{C}$ ratio than the original MeDec. Substituted cycloalkanes are the dominant products at low temperature [9], which justifies the use of cyclohexane, 1,2-diethyl, 3methyl as a model compound in the present work.

\section{Materials and methods}

\subsection{Materials}

The catalyst, extruded zeolite-X with supported palladium ( $0.5 \%$ by weight) [9] was ground to a fine mesh powder. 
(a) Pd/REX/MeDec, Gaseous Product, 350C, 180min

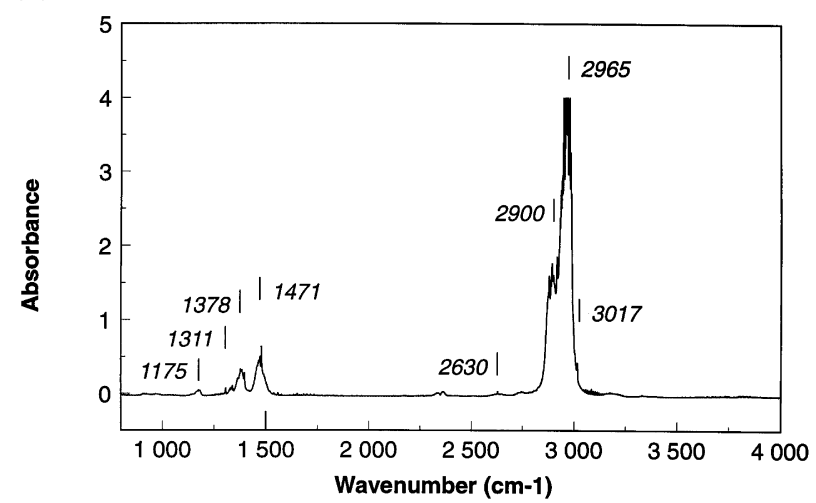

(b) Pd/REX/MeDec, Isobutane Concentration

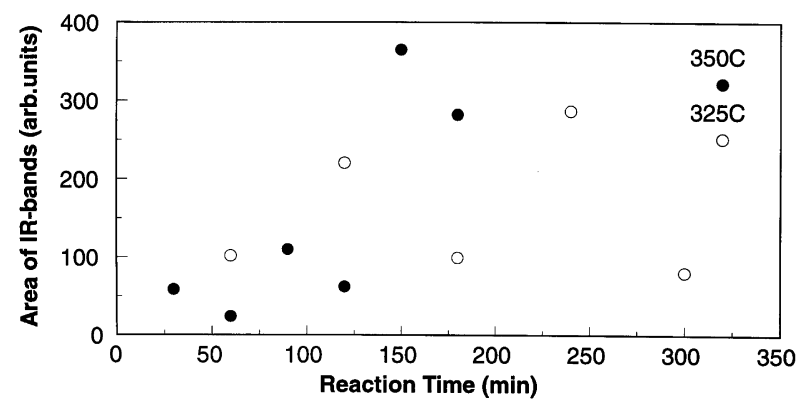

Fig. 2. (a) Infrared spectra of the gaseous product from hydrocracking of MeDec over Pd/REX; $\mathrm{p}\left(\mathrm{H}_{2}\right)=2$ bar. Characteristic bands are marked in the figure. (b) iso-Butane concentration vs. reaction time for reaction temperatures 325 and $350^{\circ} \mathrm{C}$. The iso-butane concentration was taken as the sum of the intensities of the 1378, 1471, 2900 and $2965 \mathrm{~cm}^{-1}$ bands. Literature also reports weaker bands at 1172 and $2630 \mathrm{~cm}^{-1}$ for iso- $\mathrm{C}_{4} \mathrm{H}_{10}$ [17]. The bands at 1311 and $3017 \mathrm{~cm}^{-1}$ show the presence of methane in the gaseous product.

The feed, methyldecahydronaphthalenes (MeDec), was synthesized from 1-methylnaphthalene with better than $95 \%$ selectivity $[9,10]$. It contained mainly $(>85 \%) 1-$ MeDec. Reference spectra for pure MeDec were obtained both in the vapor phase, by heating the gas cell with a droplet of MeDec, and in the liquid phase, by filling the appropriate IR and UV/Vis cells. Additional reference spectra were obtained from the literature [16-18].

\subsection{Microreactor studies: IR, UV/Vis and ESCA characterization}

Experiments in this setup addressed the time dependence of MeDec hydrocracking over Pd/REX at 325 and $350^{\circ} \mathrm{C}$. A $22 \mathrm{~cm}^{3}$ non-circulating batch microreactor (diameter $1.63 \mathrm{~cm}$, inside length $10 \mathrm{~cm}$ ) was integrated with a gascell for post-reaction, infrared analysis of gaseous products. $0.387 \mathrm{~g}$ of the feed was mixed with $0.050 \mathrm{~g}$ of the ground catalyst in the reactor. The vessel was repeatedly purged with hydrogen and sealed at 2 bar $\mathrm{H}_{2}$ and $25^{\circ} \mathrm{C}$. The temperature was increased to 325 or $350^{\circ} \mathrm{C}$ over $15 \mathrm{~min}$, kept constant for $30-300 \mathrm{~min}$ and then cooled to $25^{\circ} \mathrm{C}$ within $30 \mathrm{~min}$.

A new background spectrum, with the gas cell purged and filled with hydrogen at 2 bar, was obtained for each run during the cool-down. The gas-cell was then evacuated and opened to the reactor and a spectrum obtained, at a pressure between 1.5 and 2 bar. All infrared studies (gas, liquid and diffuse reflectance) employed a Bomem Michelson MB 152 instrument with a DTGS detector and $45 \mathrm{~min}$ signal averaging. Gas phase spectra were obtained at $2 \mathrm{~cm}^{-1}$ resolution with a $125 \mathrm{~mm}$ pathlength and $\mathrm{NaCl}$ windows.

A sample of the liquid product was retrieved from the reactor at $25^{\circ} \mathrm{C}$ and ambient atmosphere. It was subsequently analyzed by infrared spectroscopy $\left(4 \mathrm{~cm}^{-1}\right.$ resolution, $\mathrm{CaF}_{2}$ windows) with pure $\mathrm{MeDec}$, the feed, as reference. Ultraviolet-visible (UV/Vis) spectra of the liquid product were measured (Varian Cary $5 \mathrm{E}$ ), in a quartz cell (1 mm pathlength), in the $310-800 \mathrm{~nm}$ range, with a scan speed of $60 \mathrm{~nm} / \mathrm{min}$. For these measurements $100 \mu \mathrm{l}$ $( \pm 10 \%)$ of the liquid product was dissolved in $2000 \mu \mathrm{l}$ acetone. Pure acetone was used as reference and comparisons were made between a retrieved sample and pure $\mathrm{MeDec}$ in acetone.

The catalyst was flushed from the reactor with ethanol and dried overnight at $80^{\circ} \mathrm{C}$. The dried catalysts were analyzed by diffuse reflectance spectroscopy $\left(4 \mathrm{~cm}^{-1}\right.$ resolution, $\mathrm{NaCl}$ windows), with the fresh catalyst as reference, and by core level X-ray photoelectron spectroscopy. XPS spectra were obtained at $0.5 \mathrm{eV}$ resolution (steplength) with an ESCA Kratos ES-300 instrument and the Fison VGX900 software. Each run employed widescans for verification of sample cleanliness, and repeated regional scans over the $\mathrm{C}$ $1 \mathrm{~s}$ region. The intensity of the $\mathrm{C} 1 \mathrm{~s}$ peak was normalized to the $\mathrm{O} 1 \mathrm{~s}$ intensity, to avoid artifacts from the sample and the spectrometer.

\subsection{Calculations}

$\mathrm{Ab}$ initio quantum chemical calculations employed the GaUsSIAN 94 routines for Hartree-Fock calculations with $6 / 311-G$ basis functions $[19,20]$. Vibrational frequencies and orbital energies were artificially broadened to mimic experimental IR and photoemission spectra.

\section{Results and discussion}

The temperature range from 325 to $350^{\circ} \mathrm{C}$ is critical for the altered product distribution of $\mathrm{MeDec}$ hydrocracking over $\mathrm{Pd} / \mathrm{REX}$ [8-10]. Over this range the conversion improved from around $75 \%$ to above $95 \%$, but the yield of desirable products dropped, and a considerable amount of aromatics was formed. The yield of gaseous products nearly doubled, and a shift towards $\mathrm{C}_{1-3}$ molecules was observed, less desirable than iso-butane, which dominated at lower temperatures.

The present work illuminated the above results from 
(a) Pd/REX/MeDec, MeDec Concentrationion

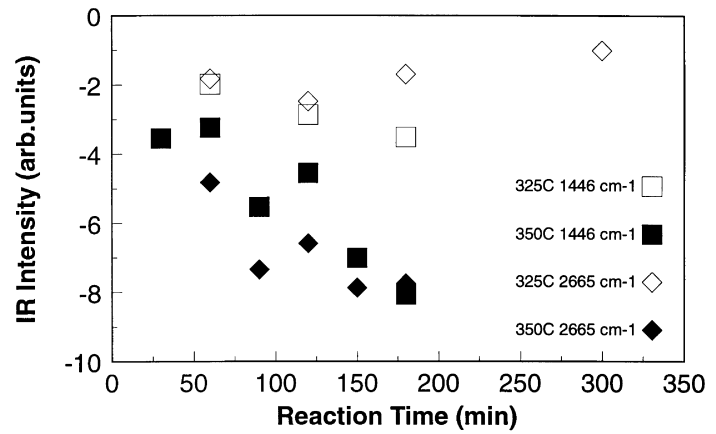

(b) Pd/REX/MeDec, Liquid Product

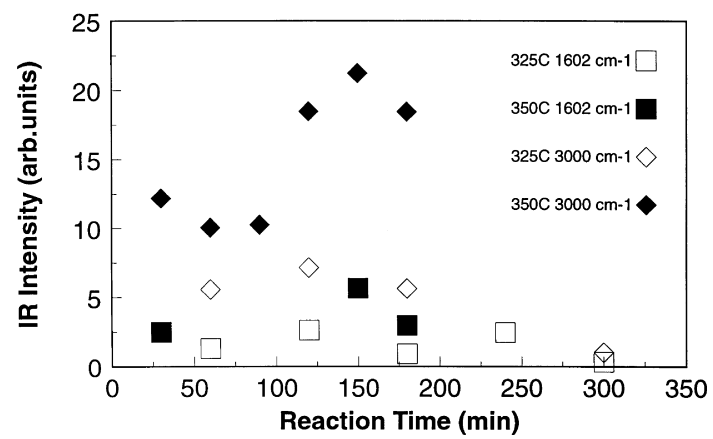

Fig. 3. (a) MeDec consumption evaluated as the intensities of characteristic bands at 1446 and $2665 \mathrm{~cm}^{-1}$. The values 1446 and $2665 \mathrm{~cm}^{-1}$ correspond to MeDec absorption bands. (b) Increase of the 1602 and $3000 \mathrm{~cm}^{-1}$ band intensities for reaction temperatures 325 and $350^{\circ} \mathrm{C}$. Intensities at 1602 and $3000 \mathrm{~cm}^{-1}$ are indicative of different aromatic compounds. Pure MeDec $(>95 \%)$ was used as reference for infrared spectra of the liquid product.

autoclave studies, with time-dependent studies and surface sensitive modeling, in the critical temperature range, but preemptive to any analysis of our surface measurements we must verify the validity of our model system, i.e. confirm that our batch microreactor, operated at 2 bar, represented similar conditions to the stirred high pressure system operated at 50 bar. As a result of thermodynamics, a lower

Pd/REX/MeDec, Liquid Product

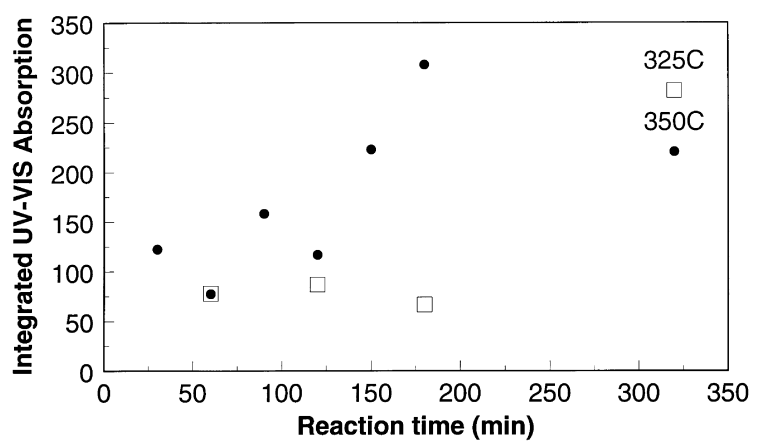

Fig. 4. Integrated UV absorption intensity (320-500 nm) vs. reaction time for reaction temperatures 325 and $350^{\circ} \mathrm{C} ; \mathrm{p}\left(\mathrm{H}_{2}\right)=2$ bar. Pure acetone was used as reference for UV/Vis spectra of the liquid product. (a) Pd/REX/MeDec, Liquid Product, 325C
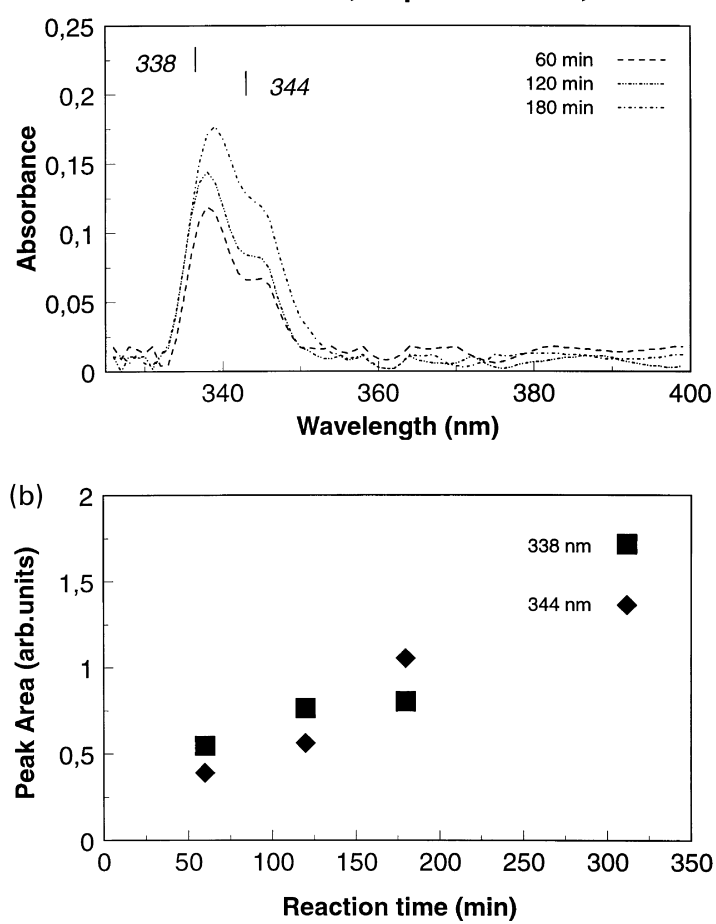

Fig. 5. (a) UV/Vis spectra of the liquid product from hydrocracking of MeDec over Pd/REX. Peak deconvolusion after subtraction of non-linear backgrounds from the original spectra; reaction temperature $=325^{\circ} \mathrm{C}$; $\mathrm{p}\left(\mathrm{H}_{2}\right)=2$ bar. (b) Increase of absorption bands at 338 and $344 \mathrm{~nm}$ vs. reaction time; reaction temperature $=325^{\circ} \mathrm{C}$.

hydrogen pressure, at constant temperature, favors the formation of aromatic compounds [21].

The gaseous product at $350^{\circ} \mathrm{C}$ was dominated by isobutane, as expected from the temperature and the above results from autoclave studies. Fig. $2 \mathrm{a}$ and $\mathrm{b}$ summarizes the evolution of the $i-\mathrm{C}_{4} \mathrm{H}_{10}$ bands (1378, 1471, 2900, $2965 \mathrm{~cm}^{-1}$ ) with time for the reaction temperatures 325 and $350^{\circ} \mathrm{C}$. The bands at 1175 and $2630 \mathrm{~cm}^{-1}$ also belong to iso-butane, although the latter assignment is somewhat controversial [17]. The band at $3017 \mathrm{~cm}^{-1}$ is characteristic of methane. We also note the $\mathrm{CO}_{2}$ bands at around $2350 \mathrm{~cm}^{-1}$, but this information is irrelevant for an unpurged spectrometer.

The decrease of unconverted MeDec in the liquid product was followed by infrared spectroscopy (Fig. 3a), with 1446 and $2665 \mathrm{~cm}^{-1}$ as two characteristic bands [10]. The growth of aromatic compounds, evaluated as the intensities at 1602 and $3000 \mathrm{~cm}^{-1}$, is displayed in Fig. 3b. Benzene, toluene and xylenes have bands between 3000 and $3100 \mathrm{~cm}^{-1}$ [18]. Intensity at $1602 \mathrm{~cm}^{-1}$ is also typical for aromatic groups, although not necessarily the same species as for the $3000 \mathrm{~cm}^{-1}$ region.

Electronic absorption spectroscopy in the UV/Vis range offers an alternate way to monitor product evolution and aromatics content. Fig. 4 compiles the integrated absorption from 320 to $500 \mathrm{~nm}$. The data for $325^{\circ} \mathrm{C}$ also contained 

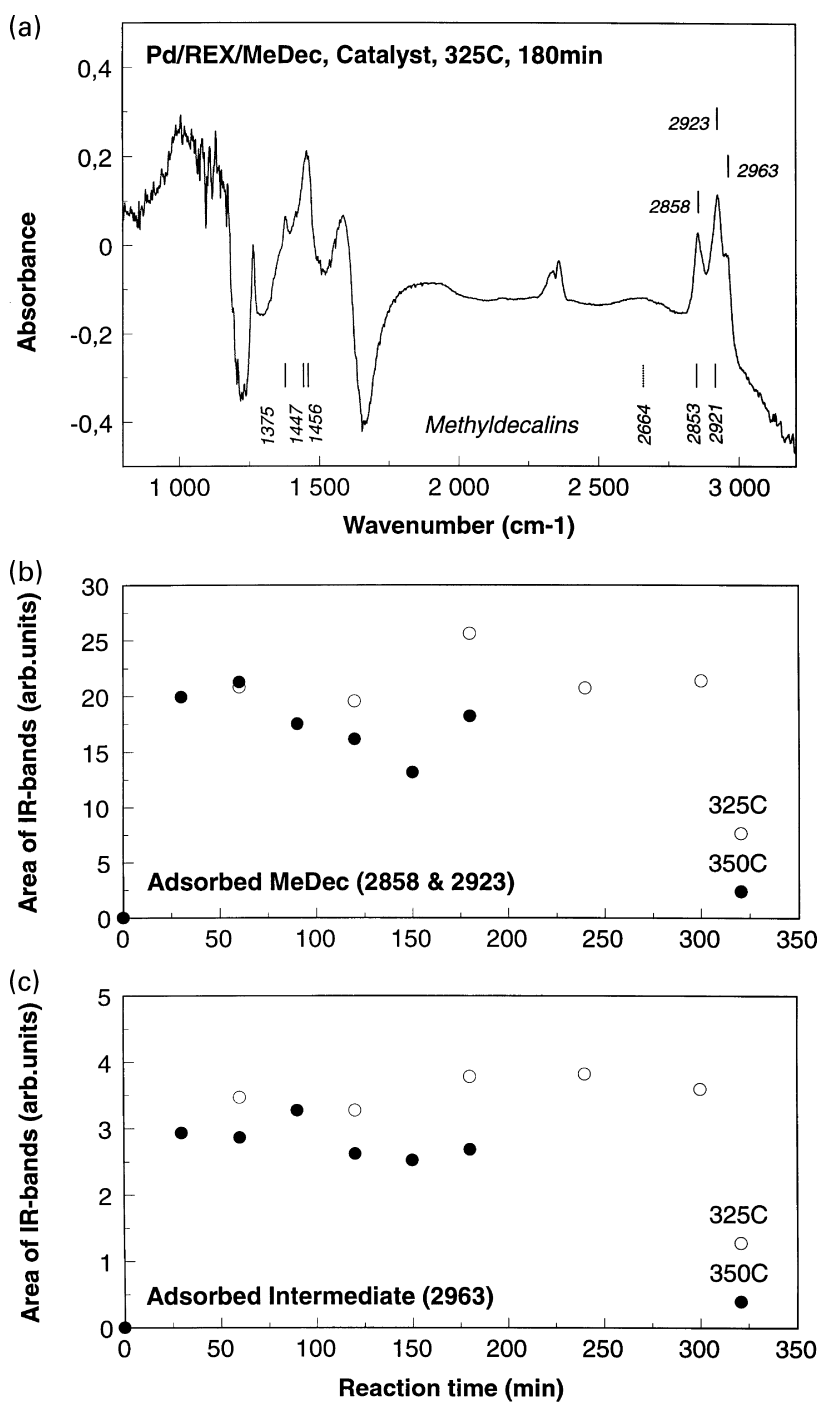

Fig. 6. (a) Diffuse reflectance IR-spectra of used catalysts following hydrocracking of MeDec over Pd/REX. The spectrum of the fresh catalyst was used as reference. Reaction temperature $=325^{\circ} \mathrm{C} ; \mathrm{p}\left(\mathrm{H}_{2}\right)=2$ bar. Characteristic bands for adsorbed MeDec, 2858, 2923 and $2963 \mathrm{~cm}^{-1}$, are marked in the figure along with peak positions for liquid MeDec; 1375, 1447, 1456, 2853 and $2921 \mathrm{~cm}^{-1}$ [10]. The peak at $2664 \mathrm{~cm}^{-1}$ is slightly controversial. (b) MeDec coverage vs. reaction time for reaction temperatures 325 and $350^{\circ} \mathrm{C}$. The coverage is given as the sum of the intensities of the characteristic bands at 2858 and $2923 \mathrm{~cm}^{-1}$. (c) IR-band intensity at $2963 \mathrm{~cm}^{-1} \mathrm{vs}$. reaction time for temperature 325 and $350^{\circ} \mathrm{C} ; 2963 \mathrm{~cm}^{-1}$ is a new band not associated with free MeDec.

some spectroscopic information (Fig. 5a). The two bands show the formation of polyaromatic hydrocarbons $(\mathrm{PAH})$. 338 and $344 \mathrm{~nm}$ are characteristic for anthracene $\left(\mathrm{C}_{14} \mathrm{H}_{10}\right)$ and naphthacene $\left(\mathrm{C}_{18} \mathrm{H}_{12}\right)$ but not for naphthalene $\left(\mathrm{C}_{10} \mathrm{H}_{8}\right)$ $[18,22]$. Peak positions and peak areas were found by background subtraction of the original spectra, followed by peak deconvolution using Gaussian shaped curves (Fig. 5a). The positions and widths were constant within $1 \mathrm{~nm}$. The intensities of both bands increase slowly with time (Fig. 5b). A similar evaluation was not possible following reactions at $350^{\circ} \mathrm{C}$, due to the high background intensity.
Both the model system (Fig. 3a) and the autoclave [8-10] showed that MeDec were converted more rapidly at $350^{\circ} \mathrm{C}$ than at $325^{\circ} \mathrm{C}$. Likewise the band at $3000 \mathrm{~cm}^{-1}$ in Fig. $3 \mathrm{~b}$ verified an enhanced yield of aromatic products. The same is true for electronic absorption spectra, which are dominated by $\pi$ to $\pi^{*}$ transitions in aromatic compounds. This plain result, eventually, links directly to fuel quality, an environmentally sound fuel, diesel or gasoline, has neither color nor odor [23]. Moreover, it has significance for in situ monitoring, UV/Vis spectroscopy has superior signal-to-noise and is thus well adapted for rapid measurements. Finally, the yield of gaseous products is higher at the higher temperature [810], but we have not pursued our model studies to discern the increase in other products than iso-butane.

\subsection{Surface species}

Fig. 6a shows an IR spectrum of the catalyst after $3 \mathrm{~h}$ in the reactor. Absorption bands of pure MeDec are given at the bottom of the figure [10]. These bands were also verified by calculations, with one exception. The band at $2664 \mathrm{~cm}^{-1}$ is observed as a low intensity peak in the present work and in gas phase spectra, but calculations do not show any intensity in this range. The broad peak from 1550 to $1610 \mathrm{~cm}^{-1}$ is typical for aromatic groups [16-18].

We used the two peaks at 2858 and $2923 \mathrm{~cm}^{-1}$ as measures of the amount of MeDec remaining on the catalyst surface (Fig. 6b). A third peak at $2963 \mathrm{~cm}^{-1}$ is associated with the catalyst surface, but has no equivalence for free MeDec. The coverage of MeDec decreased with time at $350^{\circ} \mathrm{C}$, but stayed constant at $325^{\circ} \mathrm{C}$. The same was also true for the adsorbed intermediate (Fig. 6c). This species cannot be unanimously assigned with the available data, but the high $\mathrm{C}-\mathrm{H}$ stretch frequency points at an aromatic species.

The carbon 1s ESCA peak intensity, vs. reaction time, for the two reaction temperatures, is displayed in Fig. 7. The catalysts were treated in the same way for infrared spectroscopy and ESCA with one exception. Photoemission spectroscopy means that the samples were evacuated to below $1 \times 10^{-6}$ mbar. Weakly adsorbed molecular species merely interacting with Lennard-Jones forces will unlikely remain on the surface, at room temperature, under vacuum. Hence, ESCA spectra show only chemically bound carbonaceous species.

Carbonaceous residues show a positive temperature dependence: a higher temperature leads to a higher coverage (Fig. 7). Although calibration is non-trivial, the data indicated a constant total coverage of carbonaceous residues plus molecular MeDec. It is reasonable that surface carbon influences the interaction between the catalyst and MeDec, essentially acting as a site blocker. Hence, a less number of catalytically active sites become one factor contributing to the altered product distribution.

The theoretical equivalences of infrared and photoemission spectra are displayed in Fig. 8 a and b. Fig. 9 graphically 


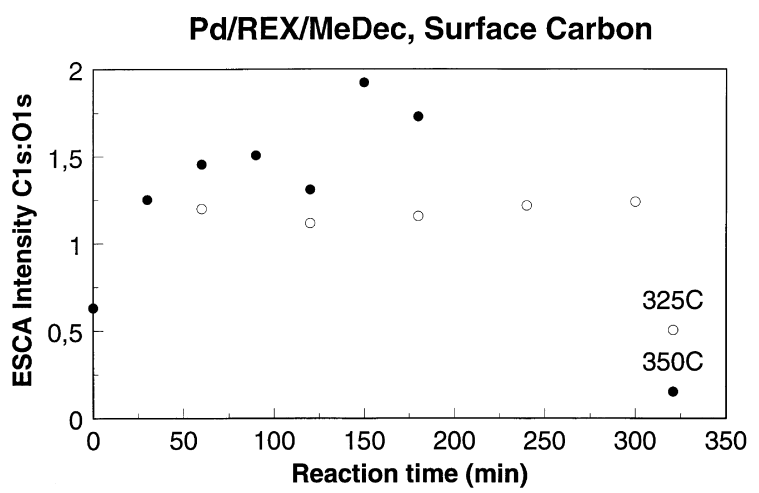

Fig. 7. Coverage of carbonaceous residues on used catalysts evaluated from the C 1s intensity of ESCA spectra. Peak position $284.6 \mathrm{eV}$ [36]. The C 1s intensity was normalized to the $\mathrm{O} 1 \mathrm{~s}$ intensity.

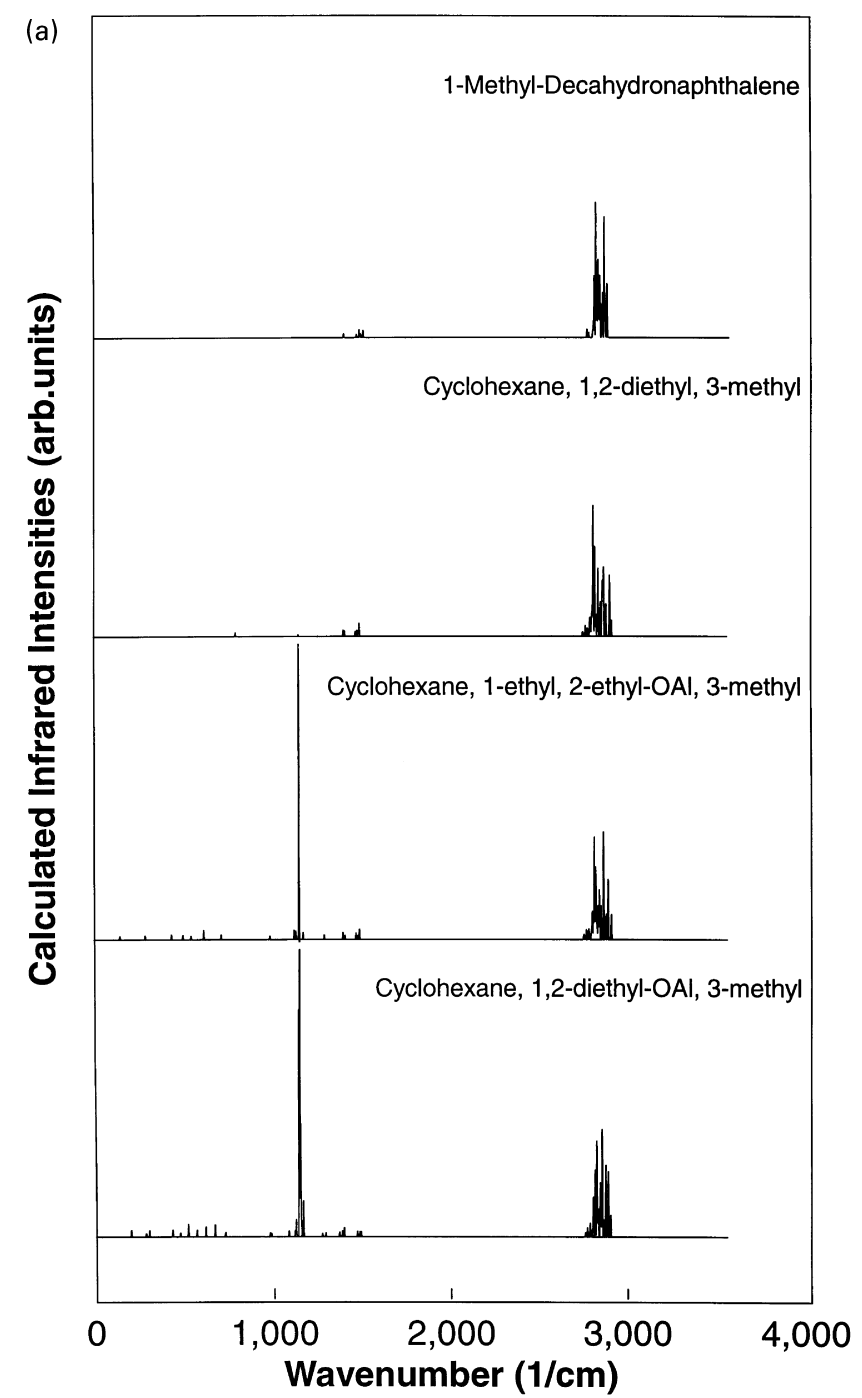

represents the optimized geometries. We consider four species: (i) 1-methyldecahydronaphthalene, in the boatform of the dominant MeDec isomer in the feed; (ii) cyclohexane, 1,2-diethyl, 3-methyl, i.e. one product of a successful ringopening reaction and a significant product [9]; (iii) cyclohexane, 1-ethyl, 2-ethyl-OAl, 3-methyl; and (iv) cyclohexane, 1,2-diethyl-OAl, 3-methyl. Here, (iii) and (iv) are catalyst bound intermediates, following ring-opening without complete hydrogenation. The Al-O distance converged at $1.69 \AA$ in the calculations compared with the experimental value $1.72 \AA$ in zeolite X [24]. All molecules were displayed using the RASMOL program [25,26].

Distinguishing the substituted cyclohexane from the feed by infrared spectroscopy is non-trivial, particularly if additional shifts due to weak interactions with the catalyst are considered, but distinct bands do occur when the molecule forms a chemical bond with the oxide (Fig. 8a). The lower two spectra in Fig. 8a reveals an intense band at around

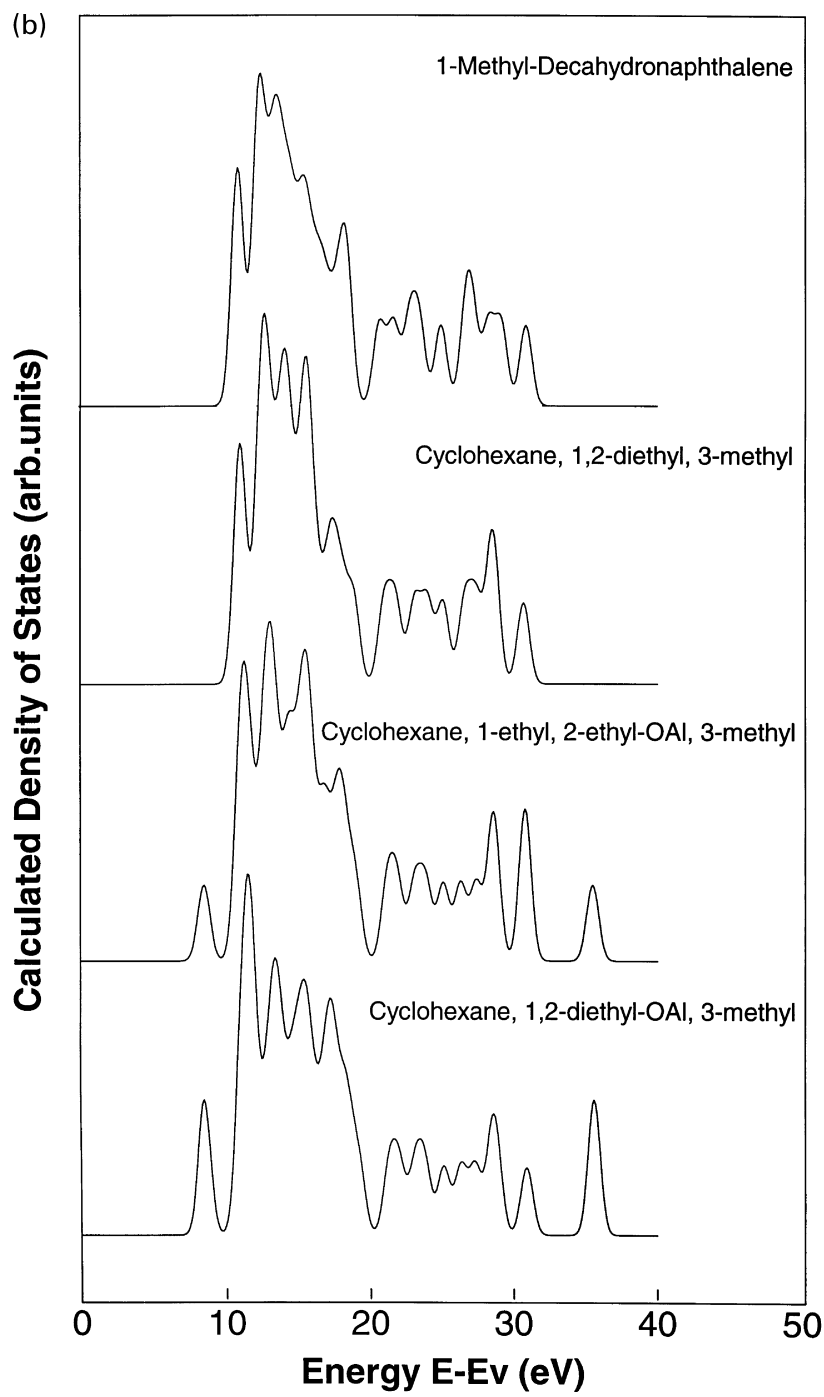

Fig. 8. Calculated (a) infrared spectra and (b) densities of states for 1-MeDec compared with cyclohexane, 1,2-diethyl, 3-methyl and two surface-bound intermediates. Cyclohexane, 1-ethyl, 2-ethyl-OAl, 3-methyl has one bond to the zeolite, and cyclohexane, 1,2-diethyl-OAl, 3-methyl two bonds to the zeolite. The densities of states are evaluated as the one-electron eigenvalues, artificially broadened to simulate valence band photoemission spectra. 


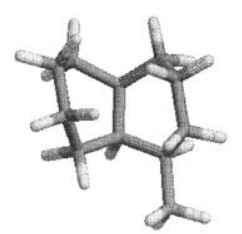

1-MeDecalin

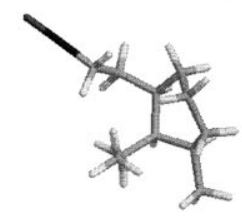

Cyclohexane, 1-ethyl, 2-ethyl-OAI, 3-methyl

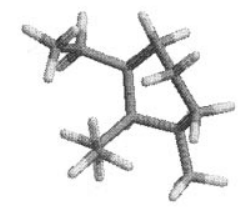

Cyclohexane, 1,2-diethyl, 3-methyl

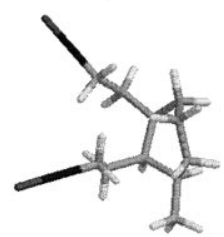

Fig. 9. Models for quantum chemical calculations of catalyst-reactant interactions. 1-MeDecalin is the feed and cyclohexane, 1,2-diethyl, 3-methyl a preferred product. Cyclohexane, 1-ethyl, 2-ethyl-OAl, 3-methyl and cyclohexane, 1,2-diethyl-OAl, 3-methyl are oxide bound intermediates on route to carbon deposition.

$1150 \mathrm{~cm}^{-1}$. This band showed only minor renormalization shifts with different effective masses of the catalyst model. It can be assigned to a single bond $\mathrm{C}-\mathrm{O}$ species. An analysis of atomic displacements during vibrational excitations of the $\mathrm{C}-\mathrm{O}$ bond further showed that the remaining hydrocarbon only moves marginally. This means that the $1150 \mathrm{~cm}^{-1}$

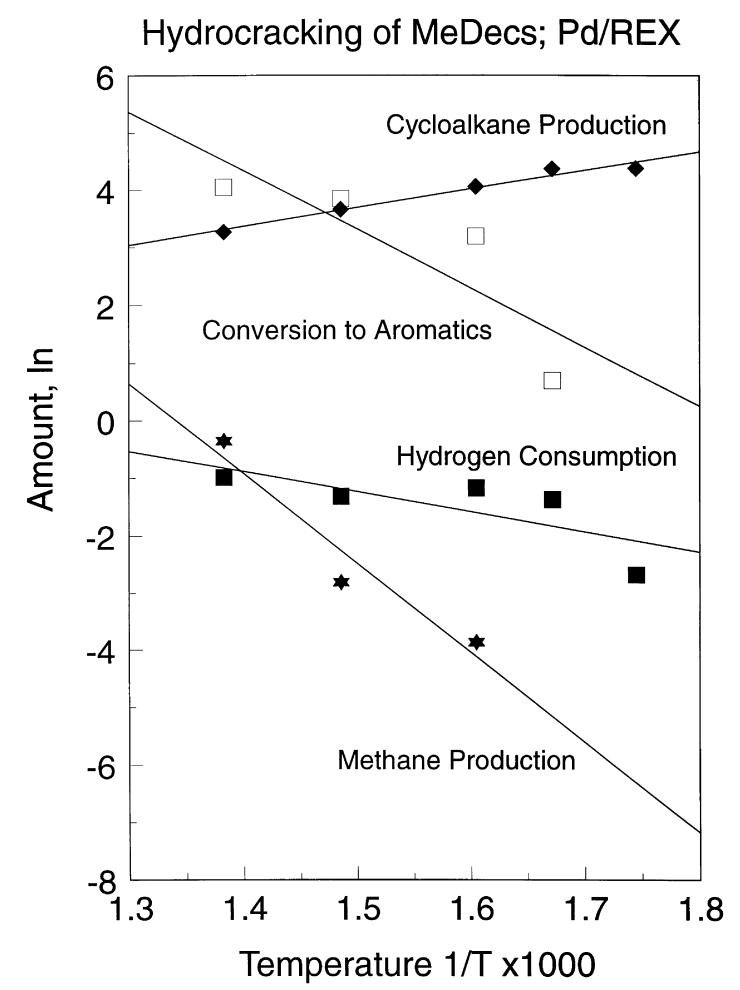

Fig. 10. Arrhenius plot of products from hydrocracking of MeDec over Pd/ REX; $\mathrm{p}\left(\mathrm{H}_{2}\right)=50$ bar; reaction time $=1 \mathrm{~h}$, derived from Ref. [9]. band is an ideal monitor for $\mathrm{C}-\mathrm{O}$ bonds between an oxidic catalyst and hydrocarbons of miscellaneous size. The frequency is directly linked to the electronic properties of the adsorption site, i.e. to surface oxygen coordination and acidity. Unfortunately reflectivity is low in this region, for the present data, but it may be possible to improve the emissivity and $\mathrm{S} / \mathrm{N}$ in a different setup (Fig. 6a).

Fig. $8 \mathrm{~b}$ shows densities of states for the above same four species. DOS is a solid state term commonly used in connection with ultraviolet photoemission (UPS) of valence bands or molecular orbitals. We conclude that UPS is not a sensitive way to monitor ring-opening reactions or the formation of an adsorption bond in the present case. The peak at $8.5 \mathrm{eV}$ stems from the catalyst model.

\subsection{Apparent activation energies and temperature effects}

Fig. 10 shows an Arrhenius plot for cycloalkane production, conversion to aromatics, methane production and hydrogen consumption over Pd/REX. The purpose is to provide insight into reaction pathways and mechanisms. Similar graphs could be drawn from data for catalytic cracking of unsubstituted polycyclic naphthenes and other tworing structures.

Hydrogen consumption and the total production of cycloalkanes are well described by Arrhenius terms with similar activation energies: $29 \mathrm{~kJ} / \mathrm{mol}$ (hydrogen consumption) vs. $27 \mathrm{~kJ} / \mathrm{mol}$ (cycloalkane production). Methane production is also well described by a single exponential term, but with a considerably larger 'activation energy' $130 \mathrm{~kJ} / \mathrm{mol}$. The conversion to aromatics indicated a more complicated volcano shape vs. temperature and it is of uncertain value to derive a single slope over the entire temperature range. The data for surface carbon would be 


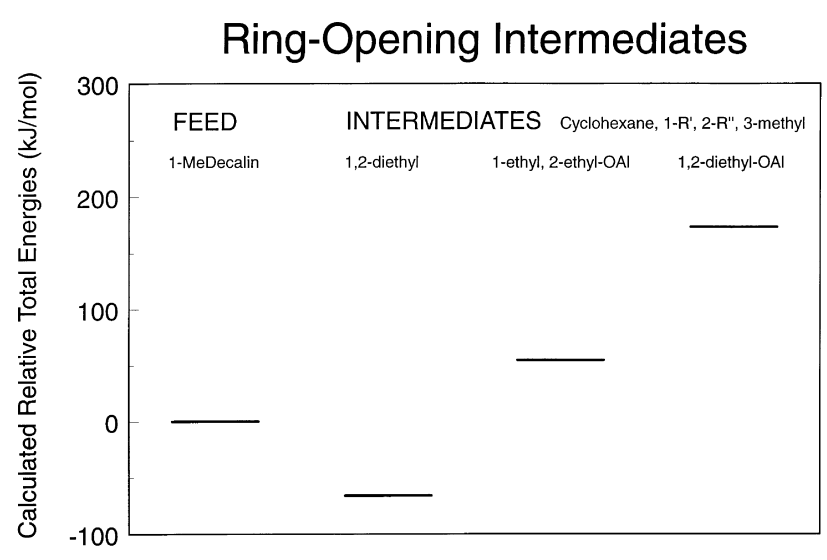

Fig. 11. Calculated total energies for 1-MeDec compared with cyclohexane, 1,2-diethyl, 3-methyl and two surface-bound intermediates. Cyclohexane, 1-ethyl, 2-ethyl-OAl, 3-methyl has one bond to the zeolite, and cyclohexane, 1,2-diethyl-OAl, 3-methyl two bonds to the zeolite.

valuable but our results represent time dependence in the initial stage rather than steady-state conditions. Our present data only allow us to make the qualitative statement that the carbon coverage increases with temperature (Fig. 7).

The slopes of hydrogen consumption and cycloalkane production have different signs. Cycloalkane production, which increases the $\mathrm{H}: \mathrm{C}$ ratio, has an optimum at low temperatures, contrary to the high temperature maximum of hydrogen consumption. Hydrogen consumption is well correlated with the total conversion [8-10]. Energies in the low-range $(27-30 \mathrm{~kJ} / \mathrm{mol})$ are typically associated with diffusion processes, but energies in the high range (130$150 \mathrm{~kJ} / \mathrm{mol}$ ) indicate reactions limited by bond dissociations [27].

Palladium is primarily responsible to refurbish dehydrogenated hydroxyl groups with hydrogen via $\mathrm{H}_{2}$ dissociation and diffusion of atomic hydrogen. Differences between Pd and other metals [9] stem from modifications of metal dispersion and specifics in the interaction potentials of molecular and atomic hydrogen on each metal.

It is desirable to enhance the conversion with maintained high selectivity for non-aromatic fuel components. The yield of cyclohexanes and cylopentanes reached a maximum between 325 and $350^{\circ} \mathrm{C}$ and decreased above this temperature [8-10]. The decrease of other cycloalkanes and cycloalkenes at higher temperatures was even faster than the decrease of cyclohexanes and cyclopentanes. Increasing the temperature to $350^{\circ} \mathrm{C}$ resulted in almost unity conversion but the drawback is a $20 \%$ yield of aromatics. Thermodynamics informs that aromatic compounds are energetically favorable at higher temperatures [21] but it is essential to discuss the role of the catalyst in the altered and less favorable product distribution.

A temperature of $325^{\circ} \mathrm{C}$ is too low for gas phase reactions, initiated by desorbing radicals; instead the preferred route must be dominated by surface reactions. The shallow temperature dependence of hydrogen consumption and cycloalkane production motivates the search for a reaction limited by diffusion. The steeper temperature dependences of aromatics and methane production show that these compounds are formed along a different route. These, less wanted, products could be the result of a homogeneous reaction initiated by desorbing radicals or competition from dehydrogenation and cleavage reactions.

The higher temperature comes with a higher coverage of surface carbon (Fig. 7). This means a lower density of acid sites available for $\mathrm{C}-\mathrm{C}$ bond breaking and hydrogen transfer. To restore the density we need to enhance the hydrogen activity by improved metal utilization and, if necessary, higher loading. The metal, Pd in the current work, produces atomic $\mathrm{H}$, which is needed to remove the surface carbon [28]. Methane production with an apparent activation energy of $130-150 \mathrm{~kJ} / \mathrm{mol}$ (Fig. 10) resembles the hydrogenation of surface carbon in Fisher-Tropsch catalysis. An enhanced hydrogen activity will also suppress the dehydrogenation of cyclohexane and MeDec, postulated precursors of aromatics [4-7].

\subsection{Mechanism}

Two steps, leading to preferred products, can be discerned for MeDec hydrocracking: (i) initial ring-opening of the two-ring structure; and (ii) cracking of the resulting substituted cyclohexane. The initial reaction should occur with excess atomic hydrogen on the catalyst surface. Hydrogen deficiency may result in cyclohexane with unsaturated substituents, a partially dehydrogenated ring or chemisorption on the catalyst surface (Fig. 9). Cyclopropane can give predominantly propylene [29], but the current reaction shows very few products with a constant or lower $\mathrm{H}: \mathrm{C}$ ratio than the feed [8-10].

The cracking of cyclohexane, or pairing reaction, converts saturated rings to branched paraffins and explains the high yields of iso-butane for substituted six-rings $[14,30]$. This reaction, as well as the initial ring-opening, enhances the $\mathrm{H}: \mathrm{C}$ ratio, and both steps involve $\mathrm{C}-\mathrm{C}$ bond breaking and hydrogen/proton transfer, although the ringopening starts with a dehydrogenation step according to some models [31].

Fig. 11 shows the calculated total energies of the three intermediate products, relative $1-\mathrm{MeDec}$. Total energies were evaluated as: (i) $1-\mathrm{MeDec}$ plus $2 \mathrm{HOAl}$; (ii) cyclohexane, 1,2-diethyl, 3-methyl plus $2 \mathrm{HOAl}$ minus $\mathrm{H}_{2}$; (iii) cyclohexane, 1-ethyl, 2-ethyl-OAl, 3-methyl plus HOAl; and (iv) cyclohexane, 1,2-diethyl-OAl, 3-methyl plus $\mathrm{H}_{2}$. Cyclohexane, 1,2-diethyl, 3-methyl is a preferred product, as well as a suitable intermediate for further cracking. The energies represent enthalpies, and the free energies can come in a different order [21], but ring-opening is energetically favorable as long as atomic hydrogen is abundant.

Superior yields of preferred products are obtained, if complete hydrogenation precedes the hydrocracking reaction [8]. The main criterion for the hydrocracking catalyst 
will then be geometry [32]. It is only the fully hydrogenated two-rings which can pass through the channels of zeolite-X without geometrical restraints (Fig. 1a and b). A lower $\mathrm{H}: \mathrm{C}$ ratio in the feed must be compensated by enhanced hydrogenation capacity. Tetralin (tetrahydronaphthalene) hydrocracking was achieved over a sulfided NiW/Zeolite-Y catalyst [14]. This catalyst have high hydrogenation activity and the hydrogenated product, contrary to tetralin, diffuses readily through the channels of the zeolite, much in the same way as decalin in the present study. Sulfided NiW or NiMo catalysts agglomerate on the support and should be located on the surface of the particles, rather than in the channels, where they will hinder the passage. This can be tailored if external acid sites are generated, these sites can anchor the metalsulfides to the support, much in the same way as Pt can be anchored to $\mathrm{Sn}^{2+}$ [33]. This role of acid sites is important and an additional aspect parallel to their direct role in the reaction [34].

Hydrogen has three roles in hydrocracking: (i) to regenerate Brønsted acid sites, potentially with the ability to break $\mathrm{C}-\mathrm{C}$ bonds and produce carbocations; (ii) to terminate radicals formed by $\mathrm{C}-\mathrm{C}$ bond breaking; and (iii) to hydrogenate and remove carbonaceous residues. Protons or neutral hydrogen atoms can either come from a protondonating molecule or from dissociated $\mathrm{H}_{2}$. A proton donating solvent is acceptable if it merely acts as a transfer agent, and a net uptake of hydrogen from $\mathrm{H}_{2}$ to the product is observed (Fig. 10). The same is true if alkane dehydrogenation occurs, it must be compensated for elsewhere, and the alkane becomes a hydrogen shuttle.

Hydrocracking is related to the chemistry of carbocations, protonation of saturated molecules, reaction propagation by radicals, isomerization and transfer of functional groups $[12,13,31,35]$. Cracking and carbonium ions are, in turn, related to hydrogen transfer, heterogeneously from the catalyst to the reactant and homogeneously between molecules [31]. Strong solid acids can facilitate $\mathrm{C}-\mathrm{C}$ bond weakening and carbonium ion formation, but hydrogen transfer is also necessary to cap unpaired electrons, after $\mathrm{C}-\mathrm{C}$ bond cleavage, else unsaturated bonds or surface residues will form. It is from the solid catalyst that protons or atomic hydrogen are unambiguously added to the complex reactions of carbocations. We cannot easily discern if this occurs directly to the reactants or via a transfer agent, but the apparent activation energy tells us that hydrogen consumption is limited by diffusion in the present case (Fig. 10).

\section{Conclusions}

An increase in the temperature from 325 to $350^{\circ} \mathrm{C}$ is critical for the product distribution from hydrocracking of MeDec over Pd/REX. Spectroscopic analyses of gaseous and liquid fractions reveal the onset of aromatics and methane formation, between these temperatures. Apparent activation energies discern that hydrogen consumption and cycloalkane production are limited by diffusion; but methane and aromatics production by bond dissociation. Higher temperature leads to a higher coverage of carbonaceous residues and a lower coverage of reactant molecules. Theoretical modeling suggests that incomplete hydrogenation may lead to a chemisorbed precursor to coke formation, characterized by a vibrational band around $1150 \mathrm{~cm}^{-1}$.

The pore size of zeolite $\mathrm{X}$ is tailor-made for hydrocracking of MeDec. Whereas, partially hydrogenated compounds are rejected due to sterical hindrance, the almost spherical form of the fully hydrogenated two-ring compound fits hand-in-glove. This means that the molecule travels a channel of hydroxyl groups, which in turn leaves little chance for interaction with dehydrogenated sites on the catalyst. $\mathrm{C}-\mathrm{C}$ bond breaking from hydrogen transfer should be followed by the transfer of a second hydrogen to terminate the unpaired electron on carbon, or $\mathrm{C}-\mathrm{O}$ bond formation with the bare catalyst may occur. Such chemisorption bonds are on-route to carbonaceous residues. The metal, palladium in the current work, is merely an agent for hydrogen dissociation and repopulation of acid sites.

\section{References}

[1] Maxwell IE. Catalysis Today 1987;1:385.

[2] Sadeghbeigi R. Fluid catalytic cracking handbook. Houston: Gulf Publishing, 1995.

[3] Hästbacka K, editor. NESTE—from oil to plastics Porvoo: Neste OY, 1993.

[4] Yan TY. Ind Engng Chem Res 1989;28:1463.

[5] Yan TY. Ind Engng Chem Res 1990;29:1995.

[6] Yan TY. Ind Engng Chem Process Des Dev 1983;22:154.

[7] Yan TY. Chem Engng Commun 1983;21:123.

[8] Demirel B, Wiser WH, Oblad AG, Zmierczak W, Shabtai J. Fuel 1998;77:301.

[9] Demirel B. Production of high octane gasoline components by hydroprocessing of coal-derived aromatic hydrocarbons, $\mathrm{PhD}$ thesis, University of Utah, Salt Lake City, 1996.

[10] Demirel B, Wiser WH. Fuel Process Technol 1997;53:157.

[11] Lunsford JH. Langmuir 1989;5:12.

[12] Corma A, Wojciechowski BW. Catal Rev Sci Engng 1985;27:29.

[13] Cumming KA, Wojciechowski BW. Catal Rev Sci Engng 1996;38:101.

[14] Haynes Jr. HW, Parcher JF, Helmer NE. Ind Engng Chem Process Des Dev 1983;22:401.

[15] Beecher R, Voorhies Jr. A, Eberly Jr. P. Ind Engng Chem Prod Res Dev 1968;7:203.

[16] The Aldrich library of FT-IR spectra. In: Pouchert CJ, editor. Vapor phase, vol. 3. Milwaukee: Aldrich, 1989.

[17] Schrader B. Raman/infrared atlas of organic compounds. 2nd ed.. New York: VCH, 1989.

[18] Lide DR, Milne GWA, editors. Handbook of data on common organic compounds Boca Raton, FL: CRC Press, 1995.

[19] Frisch M, Frisch Æ, Foresman JB. Gaussian 94, user's reference. Pittsburgh, PA: Gaussian Inc, 1995.

[20] Foresman JB, Frisch Æ. Exploring chemistry with electronic structure methods. Pittsburgh, PA: Gaussian Inc, 1996.

[21] Demirel B, Wiser WH. Fuel Process Technol 1998;55:83

[22] Tregrossi A, Barbella R, Ciajolo A. Computer-aided reconstruction of UV-Visible absorption spectra of PAH-loaden mixtures produced in 
rich combustion, internet document at http://hp9.irc.na.it/GNIC/ papers/tregross/tregross/tregross.html.

[23] Paul J. In: İncecik S, Ekinci E, Yardım F, Bayram A, editors. Air quality management at urban, regional and global scales, Zürich: Trans Tech Publications, 1997. p. 145.

[24] O’Malley P. Chemistry Department, UMIST, Manchester, M60 1QD, UK, downloadable from http://trigger.ch.umist.ac.uk:8081/zeolites/ web/intro.htm.

[25] RASMOL, shareware courtesy of Sayle R, Glaxo Wellcome Plc., downloadable from ftp://marlin.bio.umass.edu/pub/shareware/rasmol/ distrib/.

[26] Meier WM, Olson DH. Atlas of zeolite structure types. 3rd ed.. London: Butterworth, 1992.

[27] Levenspiel O. Chemical reaction engineering. 2nd ed. New York: Wiley, 1972.

[28] Beuther H, Larson OA. I\&EC Process Des Dev 1965;4:177.

[29] Bassett DW, Habgood HW. J Phys Chem 1960;64:769.
[30] Langlois GE, Sullivan RF. In: Gould RF, editor. Refining petroleum for chemicals, Washington, DC: American Chemical Society, 1970. p. 38.

[31] Wojciechowski BW, Corma A. Catalytic cracking, catalysts, chemistry, and kinetics. New York: Marcel Dekker, 1986.

[32] Decroocq D. Catalytic cracking of heavy petroleum fractions. Paris: Editions Technip, 1984.

[33] Meitzner G, Via GH, Lytle FW, Fung SC, Sinfelt JH. J Phys Chem 1988;92:2925.

[34] Corma A, Miguel PJ, Orchilles AV, Koermer GS. J Catal 1992;135:45.

[35] Olah GA, Prakash GKS, Summer J. Superacids. New York: Wiley, 1985.

[36] Wagner CD, Riggs WM, Davis LE, Moulder JF, Muilenberg GE, editors. Handbook of X-ray photoelectron spectroscopy Eden Prairie: Perkin-Elmer Corporation, 1979. 